\title{
Evaluation of Postvaccinal Antibody Responses to Three Brands of Combined Vaccines Containing Canine Parvovirus Type 2 Following Single Administration in Nigerian Local Dogs (Canis lupus familiaris)
}

\author{
O.A. Adejumobi*, D.O. Olaoba, T.O. Omobowale and H.O. Nottidge \\ Department of Veterinary Medicine, Faculty of Veterinary Medicine, University of \\ Ibadan, Nigeria.
}

$\mathbf{T}$

HE current level of morbidity and mortality among dogs due to canine parvovirus infection despite vaccination raises concerns about the effectiveness of commercially available polyvalent modified live vaccine containing Distemper, Adenovirus, Leptospira, Parvovirus and Parainfluenza antigens (DHLPPi) in Nigeria. This study was conducted to evaluate canine parvovirus type 2 (CPV-2) antibody responses to three different brands of DHLPPi vaccines. Fifteen Nigerian local dogs, age 8- 14 weeks; were randomly selected. The dogs were divided into 3 groups (A, B and C) each containing 5 dogs. The dogs were vaccinated with respective polyvalent modified live vaccines containing Distemper, Adenovirus, Leptospira, Parvovirus and Parainfluenza antigens (DHLPPi) tagged A, B and C. Blood samples were collected before vaccination weekly for four weeks and on day 90 post vaccination. The sera from the collected blood samples were subjected to Indirect Enzyme Linked Immunosorbent Assay (ELISA). The mean titre values were analysed using ANOVA test and student t-test. Group A had a statistical significant $(\mathrm{P}<0.05)$ higher antibody titre when compared with that of group $\mathrm{B}$ on day 21. A statistical significant $(\mathrm{P}<0.05)$ increase in antibody response was found in group Bwhen compared to group A on days 14 and 28 and group $C$ on day 14. Group C had significantly higher antibody titre when compared to group A on days 7 and 28 and group B on day 21 .

The group $\mathrm{C}$ antibody titres were found to be the consistently higher than those of groups A except on days 14 and 21 and and group B on every other days except on days 14 and 90.

In conclusion, the three vaccines were found to be immunogenic, but vaccines $\mathrm{B}$ and $\mathrm{C}$ gave adequate and consistently high immune response whilevaccine A gave the least response. The occurrence CPV enteritis in dogs despite vaccination may therefore, be attributed to vaccine failure as a result of poor immunogenicity of some vaccines used in routine vaccination of dogs and other factors that may affect the quality of vaccine or ability of the host to produce adequate antibody to administered vaccines.

Keywords: Canine parvovirus 2, Dog, ELISA, Antibody, Immunogenicity.

\section{Introduction}

Canine parvovirus is a small, non-enveloped and single stranded DNA virus belonging to the family Parvoviridae [1]. Canine parvovirus (CPV2) belongs to genus Parvovirus and it is related to feline pan-leukopenia virus (FPV), mink enteritis virus (MEV) and raccoon parvovirus (RPV) [2].

CPV2 causes acute, highly contagious, sometimes fatal enteritis in dogs [3] and acute haemorrhagic enteritis and myocarditis in puppies over the age of 3-4 months [4]. The virus replicates in the intestinal crypts and the lymphoid organs and it can spread to all tissues [5], including the brain $[6,7]$. After penetration through the oronasal route, the virus replicates in gastro-enteric associated lymphoid tissues and is disseminated by infected leukocytes to the germinal epithelium of the crypts of the small intestine, causing diarrhoea and acute lymphopenia [5].

The disease is more severe in younger animals, it may be asymptomatic in adult dogs. Infected adult dogs may be apparently healthy but may act as carriers of the virus to other susceptible animals [8].It was reported that breeds like Rottweiler, America pit bull terriers, Doberman pincher and German shepherd dogs (GSDs) are at higher risk of CPV infection than breeds like Toy poodles, cocker spaniel and mixed breeds [9]. 
The most common form of the disease is enteritis [9] which is clinically characterized by vomiting, diarrhoea, dehydration, dark or bloody faeces, fever and leukopenia counts [10]. The most dramatic manifestation of CPV2 myocarditis is sudden death in young pups usually about 4 weeks of age [11]. The mortality may be very high (up to $70 \%$ ) in pups but much less in adult dogs. The haemorrhagic enteritis, majorly of the small intestine and enlargement of the mesenteric lymph nodes and payer patches are the main gross signs found in dogs at necropsy [12].

Effective vaccines like modified live (ML) and inactivated parvovirus vaccines have been used to fully protect susceptible sero-negative pups [13]. The only concern is the ability of the vaccine to protect against challenges of any of the three serotypes, namely CPV-2a, CPV-2b, and CPV-2c [14]. Greenwood et al. [15] however reported that live attenuated CPV2 vaccine is able to protect dog against CPV $2 \mathrm{a}$ and CPV $2 \mathrm{~b}$ field challenges.

Commercially available CPV-2 vaccines are marketed and administered in combination with distemper, hepatitis, leptospirosis, and parainfluenza vaccines (DHLPPi) [16].

It is recommended that puppies be given a series of vaccinations to stimulate active immunity as maternally derived immunity declines [17].

However, the usefulness of annual revaccination of vaccinated dogs is still widely debated because of high occurrence of CPV enteritis with attendant high mortality and morbidity [18, 19and 20]. Early studies have also demonstrated interference of vaccination of puppies by maternally derived antibody (MDA) [21]. It was also reported that colostral transfer account for approximately 90\% of MDA [22, 23]. Puppies and kittens from unvaccinated dams have no inhibitory MDA and may be easily susceptible to infection [24]. The interference with the immune response to vaccination by the MDA may result in vaccine failure and CPV infection. MDA interference in such puppies may last up to 40 - 69 days [25]. In the absence of MDA blockade, the onset of protection against CPV infections is as early as 3 days post vaccination [17]. Pups with low protective antibody can be vaccinated by six weeks while those with higher protective antibody should be delayed for more weeks [17]. Optimum age at which a pup should be vaccinated should be determined by serologic tests of MDA taking into consideration the halflife of MDA which is about 9-10 days [17]. The fact that canine parvovirus enteritis still occurs in dogs despite vaccination informed this study.

This study was carried out to investigate the immunogenicity of $\mathrm{CPV}-2$ vaccines in three brands of polyvalent DHLPPi vaccines commonly used for routine vaccination of dogs in Nigeria. The study also aimed at determining the trend of antibody titres to the vaccines in other to determine the optimum time for a booster dose in indigenous dogs.

\section{Material and Methods}

\section{Experimental animals}

Fifteen apparently healthy Nigerian local puppies, age 8 - 14 weeks, were procured from a dog breeder in Ibadan, Oyo-State, Nigeria. The dogs were acclimatized for a period of 5 weeks during which they were dewormed and certified to be free of infection. They were thereafter divided into three groups; A, B and C in separate pens with each group containing five dogs. They were fed on home cooked meals and provided water ad-libitum.

Blood sample was collected from each dog before the vaccination of the dogs and thereafter, dogs in groups A, B and $\mathrm{C}$ were administered vaccines labelled $\mathrm{A}, \mathrm{B}$ and $\mathrm{C}$, respectively. A single dose of their respective brands of polyvalent modified live vaccines containing Distemper, Adenovirus, Leptospira, Parvovirus and Para-influenza antigens (DHLPPi) were administered subcutaneously. After the vaccination, blood samples were collected weekly for 4 weeks and thereafter on day 90 post vaccination. All the animals received humane care according to the criteria outlined in the Public Health Service Policy on Humane Care and the Use of Laboratory Animals [26].

Sample Collection and serum preparation

Blood was collected via jugular venipuncture using 21-guage needles and $5 \mathrm{ml}$ syringes.

Blood was collected into plain and EDTA tubes for serology and haematology respectively.

Blood samples collected in plain bottles were centrifuged at $5000 \mathrm{rpm}$ for 15 minutes and serum samples were harvested and stored at $-20^{\circ} \mathrm{C}$ till they were analysed. 


\section{Serological Analysis}

A commercial antibody detection ELISA (indirect) test kit manufactured by INGENASA, C/Hnos, Garcia Noblejas, 3928037 - MADRID, SPAIN was used for the detection of antibodies to $\mathrm{CPV}$ in serum following the manufacturer's protocol.

Test sera were diluted using $1 / 100$ dilution factor in the diluent and wash solution was diluted using 1 part concentrated wash solution and 9 parts distilled water. About $100 \mu \mathrm{l}$ each of control negative and positive samples were dispensed into duplicate wells. Test samples $(100 \mu \mathrm{l})$ were also dispensed per well and incubated for 10 minutes at room temperature. Excess reagent was tapped-off the plate and washing was done by dispensing $300 \mu 1$ of wash solution per well as instructed by the manufacturer. The plate was emptied and the excess was tapped out on paper towel. The procedure was repeated four times after which $100 \mu 1$ of conjugate (Peroxidase- labelled MabanticanineIgG) was immediately dispensed into each well and allowed to incubate for 10 minutes at room temperature. The plate was emptied and washed as earlier described. Thereafter, $100 \mu 1$ of substrate, 3, 3', 5, 5', Tetramethyl [1, 1',-biphenyl]-4, 4'-diamine (TMB), was immediately dispensed into each well and allowed to incubate for another 5 minutes at room temperature. Stop solution $(100 \mu 1)$ was immediately dispensed into each well. The absorbance of each well was read using an ELISA plate reader at $450 \mathrm{~nm}$ within 5 minutes after the addition of stop solution.

\section{Calculations and interpretation of results}

The serum CPV antibody titre was calculated as described in the ELISA kit manufacturer's protocol (INGENASA, C/Hnos, Garcia Noblejas, 3928037 - MADRID, SPAIN).

Percentage increase in antibody was calculated using the formula $A_{1}-A_{0} / A_{0} \times 100 \%$. Where $A_{1}$ $\mathrm{A}_{0}$ is the difference in antibody titres and $\mathrm{A}_{0}$ is the initial antibody titre.

\section{Statistical analysis}

The result of the ELISA antibody titres were calculated using proportion and descriptive statistics. The mean values obtained were compared for significant differences using ANOVA and student t-test.

\section{$\underline{\text { Results }}$}

The mean CPV antibody titres for all the groups from day 0 to day 28 and day 90 postvaccination is presented in table 1 below. At day 0 , the mean CPV antibody titre of group A was $3168.50 \pm 75.39$, while those of $\mathrm{B}$ and $\mathrm{C}$ were $2645.75 \pm 190.23$ and $3238.75 \pm 161.94$ respectively.

On day 7 , a statistically significant $(\mathrm{p}<0.05)$ decrease in mean CPV antibody titre was observed in group A $(3159.2 \pm 167.05)$ when compared to that of group $\mathrm{C}(3608.5 \pm 268.11)$. The mean titre of group B $(3450.50 \pm 270.10)$ was higher than that of group A, but less than that of group C (3608.5 \pm 268.11$)$ although these differences were not statistically significant. On day 14 also, the mean $\mathrm{CPV}$ antibody titres in groups $\mathrm{A}, \mathrm{B}$ and $\mathrm{C}$ were $3507.0 \pm 285.48,3822.75 \pm 336.22$ and $3264.0 \pm 143.42$ respectively (Table 1 ). The mean CPV antibody titre value of group $\mathrm{B}$ was statistically significantly higher $(\mathrm{P}<0.05)$ than that of groups A and C.

On day 21 , the mean titres in groups A, B and $\mathrm{C}$ were $3732.75 \pm 183.02,3114.75 \pm 154.34$ and $3689.5 \pm 212.38$ respectively, with value of group A being statistically significantly higher $(\mathrm{P}<0.01)$ when compared to that of group B. Also, mean titre value of group B had a significantly lower $(\mathrm{P}<0.01)$ value than that of group $\mathrm{C}$.

At day 28 also, the mean $\mathrm{CPV}$ antibody titres in groups A, B and C were $3008.75 \pm 282.74$, $3512.0 \pm 182.32$ and $3587.50 \pm 204.19$ respectively, with value of group A being statistically significantly lower $(\mathrm{P}<0.05)$ than that of group $\mathrm{B}$, and group $\mathrm{C}(\mathrm{P}<0.01)$.

At day 90, the mean titres in groups A, B and $\mathrm{C}$ were $3342.3 \pm 208.84,3517.667 \pm 143.81$ and $3393.33 \pm 137.31$ respectively. The mean CPV antibody titre value of group B was higher than those of both groups A and C. The mean CPV of group $\mathrm{C}$ is next to that of group $\mathrm{B}$ while that of group A was the least. These differences were however not statistically significant (Table 1)

The trend and relative percentage changes invaccinal antibody response to the brands of vaccines administered are presented in figure I and table 2 below. Dogs in group A showed an initial rise in mean CPV antibody titre from day 7 $(-0.29 \%)$ till day $21(10.7 \%)$ followed by a drop on day $28(-5.04 \%)$ before another steady rise till day 
$90(5.49 \%)$. In group B, there was a significant rise in mean CPV antibody titre from day 0 through day $7(30.42 \%)$ till day $14(44.49 \%)$. It however declined on day $21(17.73 \%)$ but rose steadily from day $28(32.74 \%)$ to day $90(32.96 \%)$. CPV antibody titre in group $\mathrm{C}$ rose from the basal level by $11.43 \%$ on day 7 . It however dropped on day $14(0.78 \%)$ but rose to the peak on day 21 $(13.92 \%)$ after which it began to drop through day $28(10.79 \%)$ to day $90(4.77 \%)$ (Table 2$)$.

TABLE1. ELISA CPV antibody titres (Mean \pm SD)in Nigerian Local dogs vaccinated with different brands DHLPPi vaccine.

Groups (Mean and Standard Deviation of Antibody Titres)

\begin{tabular}{cccc}
\hline $\begin{array}{c}\text { Sampling Period (Post- } \\
\text { Vaccination) }\end{array}$ & Group a & Group b & Group c \\
\hline DAY 0 & $3168.50 \pm 75.39$ & $2645.75 \pm 190.23$ & $3238.75 \pm 161.94$ \\
DAY 7 & $3159.2 \pm 167.05$ & $3450.50 \pm 270.10$ & $3608.5 \pm 268.11^{\mathrm{a}}$ \\
DAY 14 & $3507.0 \pm 285.48$ & $3822.75 \pm 336.22^{\mathrm{a}, \mathrm{c}}$ & $3264.0 \pm 143.42^{\mathrm{b}}$ \\
DAY 21 & $3732.75 \pm 183.02$ & $3114.75 \pm 154.34^{\mathrm{a}^{* *}}$ & $3689.5 \pm 212.38^{\mathrm{b}^{* *}}$ \\
& & & \\
DAY 28 & $3008.75 \pm 282.74$ & $3512.0 \pm 182.32^{\mathrm{a}}$ & $3587.50 \pm 204.19^{\mathrm{a}^{* *}}$ \\
& & & \\
\hline
\end{tabular}

Values with different superscripts within columns are significantly different $(\mathrm{P}<0.05)$.

Asterisks within rows show significant difference.

TABLE 2. Percentage serum antibody production to CPV antigen in Local dogs immunised with different brands of DHLPPi vaccines.

\begin{tabular}{|c|c|c|c|c|c|c|c|}
\hline $\begin{array}{l}\text { Sampling } \\
\text { (Days) }\end{array}$ & Period & 0 & 7 & 14 & 21 & 28 & 90 \\
\hline Group A (\%) & & 0 & -0.23 & 10.70 & 17.81 & -5.04 & 5.49 \\
\hline Group B (\%) & & 0 & 30.42 & 44.49 & 17.73 & 32.74 & 32.96 \\
\hline Group C (\%) & & 0 & 11.43 & 0.78 & 13.92 & 10,77 & 4.77 \\
\hline
\end{tabular}




\section{CPV ELISA}

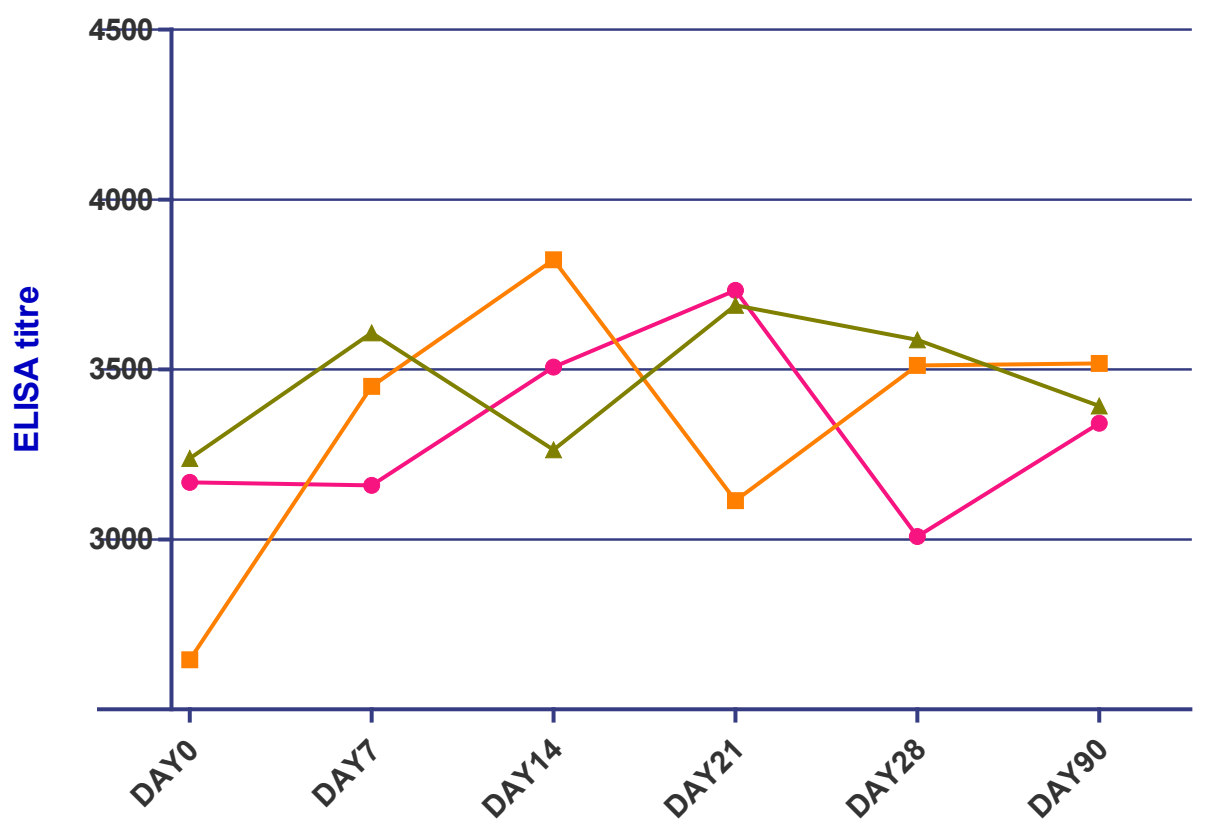

Fig. 1. Line graph showing Canine parvovirus vaccinal antibody titres in Nigerian local dogs vaccinated with a single dose of three brands of DHLPPi Vaccines.

\section{Discussion}

The purpose of vaccination is to protect individuals from infectious diseases by enhancing a specific immune response [27]. This immune response takes advantage of memory $\mathrm{B}$ cells produced by the $\mathrm{B}$ cells on primary exposure to an antigen in and this help the animal to produce a faster and better secondary immune response following a second exposure to the same antigen. ELISA test used in this study was to quantify the specific antibody to CPV vaccines from the multivalent vaccine administered. ELISA test was reported to be a veritable tool that can be used to confirm protective level of antibody at a relatively low cost [28]. Elisa test was recommended to be primarily used to validate vaccine efficacy induced by primary vaccination and to establish vaccination protocol suitable for each dog [28, 29].

Antibody titre observed on day 0 was possibly due to waning maternal antibody (MDA) passed from their dams through colostrum. The mothers however had no history of vaccination but may have acquired the antibody from natural subclinical infection.
Following vaccination, antibody was produced within a week as evident by the significant increase in the antibody titres across the three groups. This observation is similar to a report that stated that multivalent vaccine induce different immune responses to different immunogenic agents [30]. Some other researchers also reported that live attenuated CPV-2 vaccine is able to protect dogs against CPV-2a and CPV-2b field challenge [15]. Spibey et al. [31] also reported a cross reactivity and protection of CPV-2 vaccine on $\mathrm{CPV}-2 \mathrm{c}$ virus despite the antigenic variance

Antibody production following vaccination was observed after day 7 in group A in contrast to groups $\mathrm{B}$ and $\mathrm{C}$ which had earlier onset of antibody response shortly after the administration. The observed delay in antibody response till after day 7 in group A compared to the other two groups showed a prolonged lag phase of immune response. The reason for this prolonged lag phase in group A can be attributed to lower immunogenic of the vaccine A compared to vaccines $\mathrm{B}$ and $\mathrm{C}$. Group A antibody titre was observed to increase steadily from day 7 through days 14 and 21 . It 
however wane on day 28 , but rose again on day 90. Group A however, had the least antibody titre on day 90

The mean antibody titre values of vaccines B increased steadily from day seven thus showing a shorter lag period between exposure and antibody production and high immunogenicity. The antibody titre however declined on day 21 but the value rose again on day 28 and was sustained till day 90. Group B had the highest titre on day 90. Group B consistently had the highest percentage increase in antibody production when compared with those of groups $\mathrm{A}$ and $\mathrm{C}$. This findings showed that vaccine $\mathrm{B}$ had a short lag period and a prolonged protection from parvovirus disease steadily for a prolonged period up to 90 days post vaccination.

Group C also increased steadily on day seven (7) post vaccination to day 28 , although the value declined slightly on day 14 to almost the basal value but soon increased again on day 21 to day 28 to maintain a mean titre value lower than that of group B but higher than that of group A on day 90.

Comparatively, Group B vaccine offer the best protection against the parvovirus disease because of the early onset of antibody production, consistently highest relative increase in antibody production and maintenance of the highest of the antibody titre on day 90 when compared to others.

The antibody titres of the three groups were observed to be higher than those of their respective basal values in the groups used in this study.

This trend of antibody production titres justify the need for booster doses to be administered at intervals of 3-4 weeks, however this is dependent on the result of titre checks [32].

Persistent levels of morbidity and mortality due to $\mathrm{CPV}$ infection despite vaccination could be as a result of vaccine failure which ensues mostly from interference with maternally derived antibody and break in cold chain of vaccine administered [33]. Failure of vaccination as a result of the presence of maternally-derived antibody in puppies up to 16 weeks of age has been widely documented. It is the result of maternally-derived antibody falling below protective levels but which retains high enough levels to block an active immune response by the vaccinated puppies [34]
This persistence may also be caused by infection due to field strains of the virus (i.e. strains different from the ones used in producing the vaccine). More work needs to be done on this to know if the vaccine virus strain is protective for all the local field strains

Puppies with poor MDA may be vulnerable (and capable of responding to vaccination) at an earlier age, while those with high titre MDA will have protective antibodies against natural infection and they will invariably poorly respond to vaccination till12 weeks of age [35]

This study has shown that all the three vaccines elicited production of protective levels of antibody but vaccine B stimulates greater antibody production for a longer period. Although the antibody level of group B dogs decreased till day 28 , it is of a greater possibility that a longer lasting protection against canine parvovirus is conferred by this type of DHLPPi vaccine. A researcher, in his report, attributed variation in antibody titres to differences in maternal antibody titre, vaccine types, animal immune competence, environmental factors or individual biological differences [36]

\section{Conclusion and Recommendations}

From the findings of this present study we concluded that vaccine B brand ranked highest of the three vaccines, its antibody titres were better than those of both Vaccines $\mathrm{A}$ and $\mathrm{C}$ in immunogenicity as it elicited higher titres of antibody production in vaccinated dogs for a period of 90 days. Furthermore, a period of 21 days interval seems optimum for administration of booster dose of vaccine as deduced from the results of the antibody pattern to parvovirus vaccines in this experiment.

Based on the findings of this study, we recommend vaccines $\mathrm{B}$ and $\mathrm{C}$ for routine vaccination of Nigerian local dogs and revaccination with a booster dose of the vaccine to be done 3 weeks after the first dose. The use of booster dose is to elicit optimum, longer lasting and more protective secondary humoral immunity against Canine Parvovirus.

Further study into the antibody response to repeated administration of these vaccines is recommended.

Sero-monitoring to design vaccination program based on available vaccines is also 
advised. It is further recommended that the DHLPPi vaccine virus strain should be correlated to the field or local strain of CPV within the geographic region to ensure adequate protection of dog against the specific Canine Parvovirus in the environment.

\section{Conflict of Interest}

There is no conflicting interest among the authors and there was no external funding that could influence the outcome of the result.

\section{Acknowledgement}

We appreciate the contribution of Prof. O. Adeyefa and Dr O.T. Jeremiah for giving us the kennel facility and Prof. Oluwayelu who assisted in sourcing for ELISA kit. We also appreciate Mr Momoh, an animal handler in the Veterinary Teaching Hospital for his technical support.

\section{References}

1. Nakamura, M., Tohya, Y., Miyazawa, T., Mochizuki, M., Phung, H.T., Nguyen, N.H., Huynh, L.M., Nguyen, L.T., Nguyen, P.N., Nguyen, P.V., Nguyen, N.P. and Akashi, H.A., Novel antigenic variant of canine parvovirus from a Vietnamese dog. Arch. Virol.149, 22612269 (2004).

2. Tattersall, P., Bergoin, M., Bloom, M.E., Brown, K.E., Linden, R.M., Muzyczka, N., Parrish, C.R. andTijssen, P., Family Parvoviridae., In: Fauquet, C.M., Mayo, M.A., Maniloff, J., Desselberger, U., Ball, L.A. (Ed.), Virus Taxonomy: VIIIth Report of the International Committee on Taxonomy of Viruses. Elsevier Academic Press. (2005).

3. Appel, M.J.G., Scott, F.W., and Carmichael, L.E., Isolation and immunization studies of a canine parvo-like virus from dogs with hemorrhagic enteritis. Veterinary Record, 105, 156-159 (1979).

4. Hoelzer K. and Parrish C.R., The emergence of parvoviruses of carnivores. Veterinary Research, 41 (6), 39. (2010).

5. Pollock R.V. and Carmichael L.E., Maternally derived immunity to canine parvovirus infection: transfer, decline and interference with vaccination, J.Am. Vet. Med. Association., 180, 37-42 (1982).

6. Elia, G., Cavalli, A., Desario, C., Lorusso, E., Lucente, M.S., Decaro, N., Martella, V., and Buonavoglia, C., Detection of infectious canine parvovirus type 2 by mRNA real-time RTPCR. J. Virol. Methods, 146, 202-208 (2007).
7. Decaro, N., Cirone, F., Desario, C., Elia, G., Lorusso, E., Colaianni, M.L., Martella, V., Buonavoglia, C., Severe parvovirus in a 12-yearold dog that had been repeatedly vaccinated. Vet. Rec., 164, 593-595 (2009a).

8. Nandi, S., Kumar, M., Mohapatra T.K., and Ravishankar, C., Emergence of Canine Parvovirus-2 variants and its impact on vaccination. World Applied Sciences Journal, 23 (10), 1366-1376 (2013).

9. Adejumobi O.A., Omotosho O.O., Omobowale T.O. and Akinrinmade J.F., Retrospective study of the prevalence and pattern of Parvo viral enteritis presented at the veterinary teaching hospital, University of Ibadan, Nigeria. European Journal of Pharmaceutical and Medical Research., 4 (3), 109-113 (2017).

10. Yilmaz, Z., Pratelli, A., and Torun, S., Distribution of antigen types of canine parvovirus type 2 in dogs with hemorrhagic enteritis in Turkey. Turkish Journal of Veterinary and Animal Sciences, 29 (4), 1073 -1076 (2005).

11. Mochizuki, M., Horiuchi, M., Hiragi, H.,San Gabriel M.C., Yasuda, M., and Uno, T., Isolation of canine parvovirus from a cat manifesting clinical signs of feline pan-leukopenia. Journal of Clinical Microbiology, 34, 2101-2105 (1996).

12. Decaro, N. and Buonavoglia, C., Canine parvovirus; a review of epidemiological and diagnostic aspects, with emphasis on type 2c, Vet. Microbiol., 155, 1-12 (2012)

13. Carmichael, L.E., Joubert, J.C., and Pollock, R.V., A modified live canine parvovirus vaccine. II Immune response. Cornell Veterinarian, 73, 1329 (1983)

14. Pratelli, A., Cavalli, A., Martella, V., Tempesta, M., Decaro, N., Carmichael, L. E., and Buonavoglia, C., Canine Parvovirus (CPV) Vaccination: Comparison of neutralizing antibody responses in pups after inoculation with CPV2 or $\mathrm{CPV} 2 \mathrm{~b}$ modified live virus vaccine. Clinical and Diagnostic Laboratory Immunology, 8, 612-615 (2001).

15. Greenwood N.M., Chalmers W.S., Baxendale W., Thompson H. Comparison of isolates of canine parvovirus by restriction enzyme analysis, and vaccine efficacy against field strains. Vet Rec, 136, pp. 63-67 (1995).

Egypt. J. Vet. Sci. Vol. 50, No. 1 (2019) 
16. Greene G.E.and Appel M.J. Canine distemper in: Greene Infectious diseases of Dog and Cat, $3^{\text {rd }} \mathrm{ed}$., pp.: 25-41, Saunder/ Elsivier, St Louis, Missouri, P.A, USA. (2006).

17. Greene C.E and Decaro N. Canine viral enteritis. In: Greene infectious diseases of the Dog and Cat, $4^{\text {th }}$ ed., Elsievier Saunders, Missouri, USA Chapter 8, Pgs 68-76. (2012).

18. Martella, V., Cavalli, A., Pratelli, A., Bozzo, G., Camero, M., Buonavoglia, D., Narcisi, D., Tempesta, M., Buonavoglia, C., A canine parvovirus mutant is spreading in Italy. Journal of Clinical Microbiology, 42, 1333-1336 (2004).

19. Dacaro, N., Desario, C., Elia, G., Martella, V., Marl, V., Lavazzar, A.,Nardi, M., Bounavouglia C. Evidence of immunization failure in adult dogs infected with canine parvovirus type 2c. New Micobiologica31, 125-130 (2008).

20. Decaro, N., Martella, V., Desario, C., Bellacicco, A.L.,Camero, M., Manna, L., d'Aloja, D., Bounavoglia C. First detection of canine parvovirus $2 \mathrm{c}$ in pups with canine enteritis in spain. J. Vet. Med. Infect. Dis. Vet. Public Health, 53 (10), 468-472 (2006).

21. Gooding G.E., Robinson W.F., Maternal antibody, vaccination and reproductive failure in dogs with parvovirus infection. Aust Vet. J., 59, 170-4 (1982).

22. Carmichael, L.E., Joubert, J.C., and Pollock, R.V., A modified live canine parvovirus vaccine. II Immune response. Cornell Veterinarian, 73, 1329 (1983)

23. Burtoboy S., Charlier P., Hertoghs J., Lobmann M., Wiseman A., Woods S. Performance of high titre canine parvovirus vaccine in pups with maternally derived antibody. Vet. Rec. 128,377381 (1991)

24. Day M.J., Immune system development in the dog and cat. J. Comp Pathol. 137 Suppl 1, S10-S15 (2007).

25. Lida H., Fakuda S., Kawashima N., Yamashaki T., Aoki J., Tokita K., Morioka K.,Takarada N., Soeda T., Effects of maternally derived antibody level on antibody response to canine parvovirus, canine distemper virus and infectious hepatitis virus after vaccination in beagle puppies. Jikken Dobutsu, 39 (1), 9-19 (1990).

26. PHS (Public Health Service). Public Health Service Policy on Humane Care and the Use of Laboratory Animals. US Department of Health and Humane Services, Washington, DC. (1996).
27. Taguchi, M., Namikawa, K., Maruo, T., Orito, K., Lynch, J., Sahara, H., Antibody titers for canine parvovirus type-2, canine distemper virus and canine adenovirus type-1 in adult household dogs. Can. Vet. J., 5, 983-986. (2011).

28. Lister A., Pressler B., Volpi A., Dubovi E., Accuracy of point-of- care ELISA test kit for predicting canine parvovirus and canine distemper virus antibody concentration in dogs. Veterinary Journal, 193 (2), 363-366 (2012).

29. Coyne M.J., Burr J.H.,Yule T.A. Harding M.J., Transnan D.B., McGavin D., Duration of immunity in dog after vaccination and naturally occurred infection. Vet. Record., 149, 509-515 (2001).

30. Wilson S., Illanbas J., Siedek E. Thomas A., King V., Stirlin C., Plevova E., Salt J., Sture G. The administration of single dose multivalent (DHLPPI-4R) vaccine prevent mortality following virulent challenges with canine distemper virus, canine adenovirus and canine parvovirus. Trials vaccinol., 3 (1), 107-113 (2017).

31. Spibey N., Greenwood N.M., Sutton D., Chalmer, W.S.K., Tarpe I., Canine Parvo type 2 vaccine protect against virulent challenge with type $2 \mathrm{C}$ virus. Vet. Microbiology., 128 (1-2), 48-55 (2008).

32. Welborn, L.V., DeVries, J.G., Ford, R., Franklin, R.T., Hurley, K.F., McClure, K.D., Paul, M.A., and Schultz, R.D. American Animal Hospital Association (AAHA) canine vaccination guidelines. (2011).

33. Waner T., Naveh, A., Wudovsky, I., Carmichael, L.E. (1996) Assessment of maternal antibody decay and response to canine parvovirus vaccination using clinic-based enzyme linked immunosorbent assay. J.Vet Diagno. Invest., 8, 427-432 (1996).

34. Dogonyaro, B.B., Molecular Characterization of Canine Parvovirus Strains from Domestic Dogs in South Africa and Nigeria. M.Sc. Thesis, Department of Veterinary Tropical Disease, University of Pretoria, Pretoria, 1-106. (2010).

35. Friedrich, K. and Truyen, U., "Efficacy of parvovirus vaccines and effectiveness of two vaccination protocols", PRAKT TIER, 81 (12), P 988 (2000).

36. Tizari N.Y., Use of serologic testing to assess the immune status of companion animals $J$. Amvet. Med. Asso., 213 (1) 54-60 (1998).

(Received 14/12/2018 accepted $04 / 03 / 2019$ ) 


\section{تقييم استجابات الاجسام المضادة بعد التحصين بثلاثة انواع من فاكسبنات فيروسات البارو Canis) للكلاب بعد إعطاء جرعة والحدة في الكلاب المحلية النيجيرية فيروية PARVOVIRUS (lupus familiaris}

أوه. أ. اديجيموبي ، دي .اوه أولاوبا ، أوه. تي. أومويووالي و أنث ـ أوه نوتجدي قسم الطب البيطري ـ كلية الطب البيطري - جأمعة إيبادان - نيجيريا.

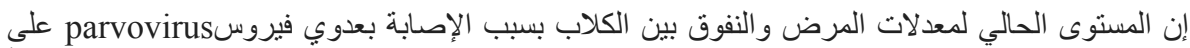

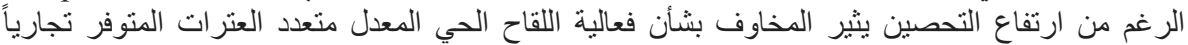

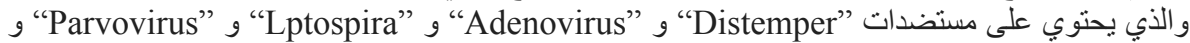
parvovirus في نيجيريا. أجريت هذه الدر اسة لتقييم استجابة الأجسام المضادة من نوع "Parinfluenza"

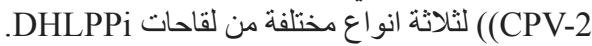

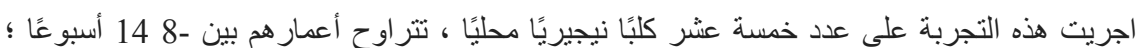

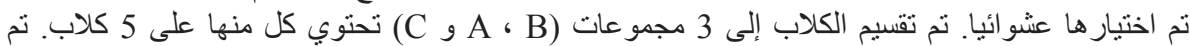

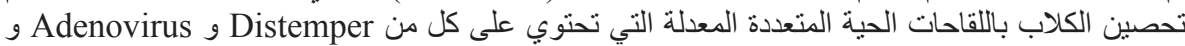

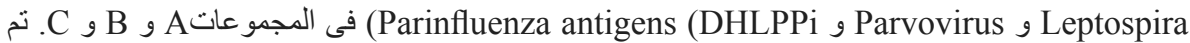

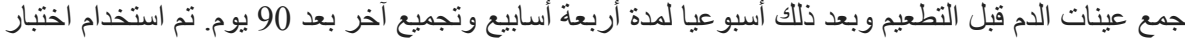

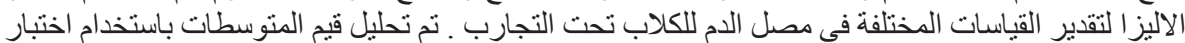
ANOVA

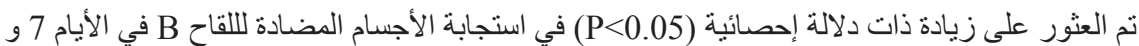

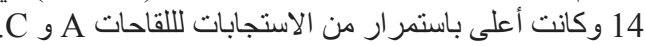

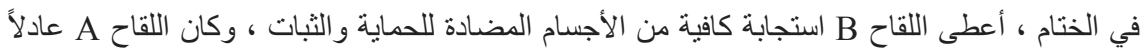

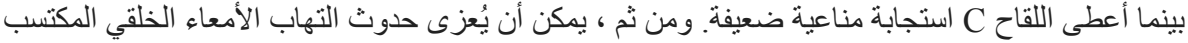

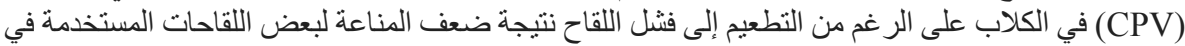
التلقيح الروتيني للكلاب.

الكلمات الرئيسية: كلاب parvovirus 2 ، الكلب ، ELISA ، الأجسام المضادة ، المناعية. 